\title{
EDITORIAL
}

\section{La Ciencia de la Sostenibilidad: una necesaria revolución científica}

Hacemos aquí un llamamiento a la comunidad educativa para que incorpore las orientaciones de la nueva Ciencia de la Sostenibilidad y contribuya a su desarrollo. Fundamentaremos este llamamiento exponiendo las causas que han originado este nuevo campo de conocimiento y resumiendo sus características esenciales, que permiten hablar de auténtica y fructífera revolución científica, a la que la educación no puede permanecer ajena.

\section{Las razones del surgimiento de la Ciencia de la Sostenibilidad}

Para explicar el surgimiento de este nuevo dominio científico, surgido al inicio de este siglo XXI (KATES et al., 2001), es preciso comenzar recordando la creciente gravedad del conjunto de problemas socioambientales que han conducido a hablar de emergencia planetaria y a introducir el concepto de Sostenibilidad. Utilizamos la mayúscula para referirnos al concepto científico y distinguirlo del uso frecuente de las palabras sostenibilidad y sostenible como simples eslóganes con significados a menudo alejados del concepto científico, e incluso contrapuestos al mismo, lo que ha llevado a Robert Engelman (2013, p. 27) a afirmar que "Vivimos actualmente en una era de la sosteniblablä'.

Este concepto surge por vía negativa, como resultado de los análisis de la situación del mundo. Una situación, fruto de las actividades humanas, que amenaza gravemente el futuro de la misma humanidad por acercarse peligrosamente a los límites del planeta e incluso haber superado ya algunos de ellos (FOLKE, 2013). Se habla por ello de una etapa geológica nueva, el Antropoceno, para destacar la responsabilidad de la especie humana en los profundos cambios que está sufriendo el planeta y que originan un conjunto de graves problemas que hacen insostenible la actual forma de vida:

Es insostenible el actual ritmo de utilización de todo tipo de recursos esenciales, desde los energéticos a los bancos de pesca, los bosques, las reservas de agua dulce y el mismo suelo cultivable. Un ritmo muy superior al de su regeneración, cuando son renovables, o al de su sustitución por otros que sí lo sean.

Es insostenible el ritmo de producción de residuos contaminantes, muy superior al de la capacidad del planeta para digerirlos: una contaminación pluriforme y sin fronteras, que envenena suelos, ríos, mares y aire y afecta ya a todos los ecosistemas.

Es insostenible, en particular, el acelerado incremento de la concentración de gases de efecto invernadero en la atmósfera, de origen claramente antrópico, que está provocando un 
desarreglo climático visible ya, entre otras muchas consecuencias, en la rápida disminución de las llamadas nieves perpetuas (la más importante reserva de agua dulce con la que cuentan miles de millones de seres humanos) y en el aumento de la frecuencia e intensidad de fenómenos atmosféricos extremos (huracanes, inundaciones, sequías e incendios...); el cambio climático contribuye así a un proceso de degradación generalizada que corre el riesgo de llegar a ser irreversible, haciendo inhabitable la Tierra para la especie humana.

Es insostenible el proceso de urbanización acelerada y desordenada -acompañado del abandono del mundo rural- que potencia los efectos de la contaminación (a causa del transporte, calefacción, acumulación de residuos, etc.) y el agotamiento de recursos (con la destrucción de terrenos agrícolas, el aumento de los tiempos de desplazamiento y consiguiente consumo de recursos energéticos, etc.).

Es insostenible el crecimiento explosivo de la población mundial, que puede estar ya cerca de sobrepasar la capacidad de carga del planeta: la especie humana acapara ya casi tanta producción fotosintética como la totalidad de las restantes especies y su huella ecológica (es decir, el área de territorio ecológicamente productivo necesaria para producir los recursos utilizados y para asimilar los residuos producidos por una población dada) ha superado ampliamente la biocapacidad del planeta.

Es insostenible la acelerada pérdida de biodiversidad, que obliga a hablar de una sexta gran extinción ya en marcha, que amenaza con romper los equilibrios de la biosfera y arrastrar a la propia especie humana, causante de esta extinción.

Es insostenible igualmente la pérdida de diversidad cultural y, muy en particular, de culturas campesinas milenarias. No debemos olvidar que la diversidad de culturas es la garantía de una pluralidad de respuestas a los problemas a los que ha de hacer frente la humanidad. Cada cultura no es solo una riqueza para el pueblo que la ha creado, sino un patrimonio de toda la humanidad.

Es insostenible e inaceptable el desequilibrio entre una quinta parte de la humanidad impulsada al hiperconsumo y miles de millones de personas que sufren hambre y condiciones de vida insoportables.

Es insostenible, en definitiva, un sistema socioeconómico guiado por la búsqueda del máximo beneficio particular a corto plazo, que apuesta por el crecimiento económico indefinido en un planeta finito, sin atender a sus consecuencias ambientales y sociales, lo que le convierte en responsable de los problemas que acabamos de enumerar y de otros igualmente graves, como las dramáticas migraciones, los conflictos y violencias causados por la competitividad, por el afán de controlar los recursos energéticos y otras materias primas esenciales y, en suma, por la destructiva anteposición de intereses particulares a la cooperación en beneficio de todos y de las generaciones futuras.

Hoy sabemos que todos estos problemas están estrechamente vinculados y se potencian mutuamente, por lo que resulta imposible resolver ninguno de ellos sin tener en cuenta los restantes (DUARTE, 2006). En ello insiste Jared Diamond, en su libro Colapso, tras analizar 12 grupos de problemas a los que se enfrentan nuestras sociedades:

Si no resolvemos cualquiera de la docena de problemas sufriremos graves perjuicios $[\ldots]$ porque todos ellos se influyen mutuamente. Si resolvemos once de los doce problemas, pero no ese decimosegundo problema, todavía nos veríamos en apuros, con independencia de cuál fuera el problema. (DIAMOND, 2006, p. 645) 
Se hace necesario, pues, integrar las aportaciones a la Sostenibilidad de distintas disciplinas que están intentando dar respuestas positiva a los numerosos llamamientos realizados para que la comunidad científica y educativa contribuyan a hacer frente a la grave situación de emergencia planetaria (LUBCHENCO, 1998; MANIATES, 2013). Esta es la razón del surgimiento de la Ciencia de la Sostenibilidad a principios del siglo XXI, con características que permiten hablar de revolución científica.

\section{Características de la nueva Ciencia de la Sostenibilidad}

La Ciencia de la Sostenibilidad surge para ayudar a comprender el sistema cada vez más complejo constituido por las sociedades humanas y los sistemas naturales con los que interaccionan y de los que en definitiva forman parte y hacer así posible el tratamiento sistémico, sin reduccionismos ni olvidos, de problemas que se potencian mutuamente. Este tratamiento global de las interacciones entre sociedad y sistemas naturales impone a la Ciencia de la Sostenibilidad tres características fundamentales que podemos resumir así (VILCHES; GIL PÉREZ, 2015):

- La nueva ciencia ha de ser profundamente interdisciplinar, puesto que aborda retos complejos en los que intervienen problemas muy diversos pero estrechamente vinculados, ninguno de los cuales puede ser resuelto aisladamente.

- Se ha comprendido igualmente que para hacer posible la transición a la Sostenibilidad es necesario incorporar a la investigación y toma de decisiones a ciudadanas y ciudadanos que no forman parte del ámbito académico, pero cuyos objetivos, conocimientos y capacidad de intervención resultan imprescindibles para definir y desarrollar estrategias viables. Se trata, pues, de una ciencia transdisciplinar.

- Las estrategias concebidas han de responder a una perspectiva amplia, tanto espacial como temporalmente. Ello implica que la perspectiva sea espacialmente "glocal" (a la vez global y local) y que temporalmente contemple tanto el corto plazo como el medio y el largo, esforzándose en anticipar posibles riesgos y obstáculos y en aprovechar tendencias positivas.

Planteamientos con esas características permiten evitar las contradicciones que a menudo afectan a medidas adoptadas para resolver problemas puntuales en el tiempo o en el espacio, que olvidan su conexión con otros problemas.

Se ha iniciado así una profunda revolución científica que integra naturaleza y sociedad: después del Heliocentrismo y de la Mecánica Newtoniana, que unificaron Cielo y Tierra, después del Evolucionismo, que estableció el puente entre la especie humana y el resto de los seres vivos, ahora asistimos a la integración del desarrollo social (económico, industrial, cultural...) con los procesos del denominado mundo natural, buscando comprender las interacciones entre la naturaleza y la sociedad a fin de favorecer a ambas y hacer posible la transición a la Sostenibilidad.

Esta nueva área de conocimiento está teniendo un notable desarrollo que está dando lugar a números encuentros internacionales, a su incorporación como nueva disciplina en un número creciente de universidades y a la creación de órganos propios de expresión en los que se publican anualmente miles de artículos, con un notable crecimiento exponencial (BETTENCOURT; KAUR, 2011; KAJIKAWA et al., 2007).

Sin embargo, tras cerca de tres lustros de existencia, la Ciencia de la Sostenibilidad sigue siendo ignorada, en general, fuera del círculo de quienes contribuyen a su desarrollo como nueva disciplina, lo que viene a limitar su objetivo básico de contribuir a la transición a la Sostenibilidad. Así lo muestran entrevistas realizadas en los campus universitarios a investigadores de distintas áreas, así como los análisis bibliográficos de las revistas internacionales. Precisamente el hecho de que la Ciencia de la Sostenibilidad se esté conformando como nueva disciplina académica puede 
explicar un desarrollo relativamente estanco, que se traduce en escasa influencia sobre el resto de la comunidad científica, educativa y movimientos sociales, contradiciendo así los principios de inter y transdisciplinariedad que están en su origen y limitando su capacidad para acelerar el proceso de transición a la Sostenibilidad, para el que se dispone cada vez de menos tiempo.

Hechos como estos hacen pensar que una profunda revolución científica, capaz de integrar el estudio del desarrollo social y de los procesos naturales, no puede darse únicamente con la creación de una nueva área de conocimiento. Por ello, la Ciencia de la Sostenibilidad, más que una nueva disciplina, ha de constituir una nueva orientación que ha de impregnar a las distintas disciplinas: el trabajo de los biólogos, economistas, educadores, físicos, geógrafos, ingenieros, químicos, etc., no puede hacerse en compartimentos estancos, sino que ha de tener presente el conjunto de las repercusiones socioambientales -tanto a corto como a largo plazo- de su actividad; y eso obliga a estudiar las aportaciones de las otras disciplinas, así como el punto de vista de los movimientos ciudadanos.

Y esta orientación ha de impregnar igualmente toda la actividad social: la de las corporaciones, sindicatos, medios de comunicación... y, muy particularmente, la actividad política. Hoy no tiene sentido, por ejemplo, que se plantee la extracción de hidrocarburos mediante la tecnología del "fracking" (fractura hidráulica) sin un análisis completo de sus consecuencias socioambientales, con la participación de distintos sectores de la comunidad científica -no solo de aquellos que estudian la viabilidad técnica del proceso- y, por supuesto, de los sectores ciudadanos implicados directa o indirectamente. Un planteamiento guiado exclusivamente por la conveniencia de reducir la dependencia exterior en la obtención de recursos energéticos puede concluir que el fracking es una buena opción (y así se afirma en numerosos informes y propuestas de los que se hacen eco los medios de comunicación). Pero la consideración de sus consecuencias sobre el territorio, de sus efectos sobre la salud humana, de su contribución al cambio climático, etc., muestran que los beneficios (particulares y a corto plazo) se ven superados por graves inconvenientes, al tiempo que desvían las inversiones del necesario impulso de las energías renovables y limpias, que constituyen la única solución sostenible al problema energético.

En esto ha de consistir la esencia de la Ciencia de la Sostenibilidad: en que las exigencias de interdisciplinariedad, transdisciplinariedad y planteamientos glocales en una perspectiva temporal amplia, impregne el trabajo de los profesionales de cualquier área, la enseñanza de las distintas disciplinas, la educación ciudadana e, insistimos, la acción política que ha de orientar el desarrollo social. No basta con una nueva disciplina, necesitamos un verdadero cambio de paradigma que afecte al conjunto de las actividades sociales, incluida la educación (CARTER, 2008). Solo así será posible avanzar en la transición a la Sostenibilidad al ritmo que la gravedad de la situación lo requiere.

Desde las páginas de Ciência \& Educação nos sumamos al llamamiento dirigido a la comunidad científica y movimientos sociales para el desarrollo de una Ciencia de la Sostenibilidad que contribuya a la necesaria y urgente superación de la actual situación de emergencia planetaria y haga posible la transición a la Sostenibilidad. Una transición para la que la Asamblea General de Naciones Unidas aprobó, en su sesión de septiembre 2015, unos Objetivos de Desarrollo Sostenible universales -fruto consensuado de una amplia participación de equipos científicos, educativos y culturales, junto a organizaciones sociales y movimientos ciudadanos-, así como una Agenda 2015-2030 diseñada para avanzar en su consecución.

Amparo Vilches

Universitat de València, Departament de Didàctica de les Ciències Experimentals i Socials, Valencia, España. E-mail: <http://www.uv.es/vilches>. 


\section{Daniel Gil-Pérez}

Universitat de València, Departament de Didàctica de les Ciències Experimentals i Socials ("jubilado en activo" en 2006), Valencia, España. Actualmente centra su actividad investigadora y ciudadana en la Alfabetización científica y la Educación para la sostenibilidad, con una especial atención a la Década de la Educación por un futuro sostenible, instituida

por Naciones Unidas para el periodo 2005-2014, que ha dado paso al actual Programa de Acción Global: un compromiso renovado por la Educación para la Sostenibilidad, así como al desarrollo de la Ciencia de la Sostenibilidad, un nuevo campo de conocimientos interdisciplinar y transdisciplinar, que incorpora a la ciudadanía en sus estudios y toma de decisiones. E-mail: <daniel.gil@uv.es>.

\section{Referencias}

BETTENCOURT, L. M. A.; KAUR, J. Evolution and structure of sustainability science. Proceedings of the National Academy of Sciences of the United States of America, Washington, v. 108, n. 49, p. 19540-19545, 2011.

CARTER, L. Sociocultural influences on science education: innovation for contemporary times. Science Education, Hoboken, v. 92, n. 1, p. 165-181, 2008.

DIAMOND, J. Colapso. Barcelona: Debate, 2006.

DUARTE, C. (Coord.). Cambio global: impacto de la actividad humana sobre el sistema Tierra. Madrid: Ed. Consejo Superior de Investigaciones Científicas, 2006.

ENGELMAN, R. Más allá de la sosteniblablá. In: THE WORLDWATCH INSTITUTE. La situación del mundo 2013: ¿es aún posible lograr la sostenibilidad? Barcelona: Icaria, 2013. p. 27-45. Disponible en: <http://blogs.worldwatch.org/sustainabilitypossible/ wp-content/uploads/2013/10/Capitulo_1.pdf > . Acceso el: 16 nov. 2015.

FOLKE, C. Respetar los límites del planeta y recuperar la conexión con la biosfera. In: THE WORLDWATCH INSTITUTE. La

situación del mundo 2013: ¿es aún posible lograr la sostenibilidad? Barcelona: Icaria, 2013. cap. 2.

KAJIKAWA, Y. et al. Creating an academic landscape of sustainability science: an analysis of the citation network.

Sustainability Science, Tokyo, v. 2, n. 2, p. 221-231, 2007.

Disponible en: <http://link.springer.com/article/10.1007\%2

Fs11625-007-0027-8>. Acceso el: 16 nov. 2015. 
KATES, R. W. et al. Sustainability science. Science, Washington, v. 292, n. 5517, p. 641-642, 27 Apr. 2001.

LUBCHENCO, J. Entering the century of the environment: a new social contract for science. Science, Washington, v. 279, n. 5.350, p. 491-497, 23 Jan. 1998.

MANIATES, M. Educar en tiempos turbulentos. In: THE WORLDWATCH INSTITUTE. La situación del mundo 2013: ¿es aún posible lograr la sostenibilidad? Barcelona: Icaria, 2013.

VILCHES, A.; GIL PÉREZ, D. Ciencia de la sostenibilidad: ¿una nueva disciplina o un nuevo enfoque para todas las disciplinas?

Revista Iberoamericana de Educación, Madrid, v. 69, n. 1, p. 39-60, 2015. Disponible en: <http://www.rieoei.org/ deloslectores/7025.pdf>. Acceso el: 16 nov. 2015.

Dirección para contacto:

Departament de Didàctica de les Ciències Experimentals i Socials. Universitat de València, Facultat de Magisteri. Avda. Tarongers 4, 46022, Valencia, Apartado de Correos 22045, España 